\title{
Stented bovine jugular vein graft (Melody valve) for surgical mitral valve replacement in infants and children
}

\author{
Luis G. Quiñonez, MD, ${ }^{\mathrm{a}}$ Roger Breitbart, MD, ${ }^{\mathrm{b}}$ Wayne Tworetsky, MD, ${ }^{\mathrm{b}}$ James E. Lock, MD, \\ Audrey C. Marshall, MD, ${ }^{b}$ and Sitaram M. Emani, MD ${ }^{\mathrm{a}}$
}

\begin{abstract}
Objective: The options for mitral valve replacement in children with irreparable mitral valve disease have been limited to fixed-diameter prostheses that do not accommodate for somatic growth. We have modified an externally stented bovine jugular vein graft (Melody valve) for implantation in this cohort. Because it is not a fixed-diameter prosthesis, we hypothesized that the valve can be expanded in the catheterization laboratory as the child grows.
\end{abstract}

Methods: The medical records of patients who had undergone Melody valve implantation in the mitral or left atrioventricular valve position from 2010 to 2013 were reviewed.

Results: Eleven patients had undergone Melody valve implantation at a median age of 7 months (range, 2-28). The techniques of valve modification and implantation included stent shortening, adding a pericardial sewing cuff, intraoperative balloon expansion, and fixation of the distal stent to the inferior left ventricle wall. The valve was competent, with a low gradient acutely postoperatively in all patients. One patient died, and one required permanent pacemaker implantation. One patient developed valve dysfunction and required explantation. Two patients without a pericardial sewing cuff developed paravalvular leaks. One patient who had not undergone distal stent fixation developed left ventricular outflow tract obstruction. Three patients who had undergone subsequent catheter-based balloon expansion of the valve have continued to demonstrate acceptable valvular function.

Conclusions: The Melody valve has demonstrated acceptable short-term function. Implantation techniques to prevent left ventricular outflow tract obstruction (suture fixation of the distal stent) and paravalvular leaks (the addition of a pericardial cuff) should be considered. The Melody valve can be percutaneously expanded as the child grows. (J Thorac Cardiovasc Surg 2014;148:1443-9)

The options for mitral valve replacement (MVR) have been limited to stented mechanical and bioprosthetic valves and the Ross mitral operation. However, mechanical and bioprosthetic valves are only available in sizes $>12 \mathrm{~mm}$ in diameter, precluding intra-annular implantation in neonates or infants with hypoplastic mitral annuli, and supra-annular implantation has been associated with poor outcomes. ${ }^{1,2}$ Moreover, because these prostheses have a fixed diameter, early reoperation for replacement will be necessary, because they will fail to accommodate for somatic growth, and fixation of the annular diameter by the prosthesis will limit the ability to upsize the valve at reoperation. $^{2-4}$ The Melody valve (Medtronic, Minneapolis, Minn) is a stent-mounted valved bovine

\footnotetext{
From the Departments of Cardiovascular Surgery ${ }^{\mathrm{a}}$ and Cardiology, ${ }^{\mathrm{b}}$ Boston Children's Hospital, Boston, Mass.

Disclosures: Authors have nothing to disclose with regard to commercial support. Received for publication April 28, 2013; revisions received Oct 15, 2013; accepted for publication Oct 27, 2013; available ahead of print Dec 12, 2013.

Address for reprints: Sitaram M. Emani, MD, Department of Cardiovascular Surgery, Boston Children's Hospital, 300 Longwood Ave, Boston, MA 02115 (E-mail: Sitaram.Emani@cardio.chboston.org). $0022-5223 / \$ 36.00$

Copyright (c) 2014 by The American Association for Thoracic Surgery http://dx.doi.org/10.1016/j.jtcvs.2013.10.059
}

jugular vein graft that has been used for transcatheter pulmonary valve replacement. ${ }^{5}$ The Melody valve has demonstrated competence for a wide range of internal diameters $\leq 22 \mathrm{~mm}$. The short-term durability of this valve under systemic blood pressure has been acceptable. ${ }^{6,7} \mathrm{We}$ hypothesized that the Melody valve could be implanted into the mitral position at a small diameter, with the potential for percutaneous balloon expansion as the child grows.

\section{METHODS}

The institutional review board approved the present study. The patients' parents or guardians provided informed consent for MVR with the Melody valve prosthesis. A retrospective chart review was performed for patients who had undergone Melody valve implantation in the mitral or left atrioventricular valve position from 2010 to March 2013. The indications for replacement, implantation techniques, and short-term outcomes have been reported.

\section{Preoperative Evaluation}

The anteroposterior and lateral annular dimensions were obtained by echocardiography to determine the suitability for Melody valve placement. A $2.5-\mathrm{cm}$ length from the midventricle to the mid-left atrium will be necessary to accommodate the valve. The annular diameter is obtained to determine the balloon size to be used during valve implantation. 


\section{Abbreviations and Acronyms \\ $\mathrm{AVC}=$ atrioventricular canal \\ $\mathrm{LV}=$ left ventricular \\ LVOT $=$ LV outflow tract \\ LVOTO $=$ LVOT obstruction \\ MVR = mitral valve replacement}

\section{Valve Preparation}

The Melody valve should be prepared before the initiation of cardiopulmonary bypass. The valve should be washed in saline, as specified by the manufacturer. The valve is approximately $2.5 \mathrm{~cm}$ long in its original configuration. For patients with small left ventricle, particularly infants, the valve can be shortened by trimming of the proximal and/or distal crowns. After trimming, the jugular vein wall should be reattached to the stent with interrupted sutures to prevent dehiscence. A strip of pericardium should be sutured around the exterior stent valve, midway between the base of the leaflet and the tips of the commissures (Figure 1,A) to facilitate suturing to the mitral annulus. Care should be taken to avoid injury to the valve leaflets, using intermittent infusion of saline to separate the valve leaflets from the valve sinuses. A sewing cuff would not be added in patients with an annular size $<12 \mathrm{~mm}$, because the cuff could impede visualization. The valve should be compressed to the minimal diameter that will admit a balloon catheter (avoiding complete obliteration of the lumen). Care must be taken to avoid asymmetric compression of the stent graft.

\section{Surgical Technique}

The mitral valve should be approached transeptally through a right atriotomy. Valve replacement should be undertaken if the mitral valve has been deemed irreparable. The posterior leaflet and supporting subvalvular apparatus should be completely resected, but the anterior leaflet should only be partially resected to elongate the distance between the valve and the left ventricular (LV) outflow tract (LVOT), particularly in patients with an atrioventricular canal (AVC) defect. Consideration should be given to anterior chord-sparing valve replacement. Most patients will require removal of the subvalvular apparatus to accommodate the length of the valve. The annulus is sized with dilators.

The prepared and compressed valve is placed in the LV inflow tract. To prevent LVOT obstruction (LVOTO), the ventricular end of the valve should be fixed to the posterior inferior wall of the left ventricle (Figure 1, B). The valve stent is secured to the muscle of the posterior LV wall using a single figure-of-eight polypropylene suture, without pledgets. We have preferred not to fix it to a chordal structure or papillary muscle, because that can still permit unfavorable mobility of the valve toward the LVOT. We have not observed disruption of this suture resulting in loss of downward canting of the Melody valve.

The valve should be anchored to the mitral annulus using a single continuous circumferential suture or multiple adjacent interrupted mattress sutures. Patients undergoing fixation with the continuous suture technique should undergo valve expansion before knot tying. The Melody valve should be expanded to 4 atm using catheterization balloons to a size not more than $1 \mathrm{~mm}$ greater than the annulus diameter measured using echocardiography. The inflow segment of the valve should be inspected to ensure that the pulmonary veins are not obstructed, and the valve leaflets should be tested with saline. The interatrial septum can be reconstituted using either autologous or bovine pericardium, increasing the capacity of the left atrium. We now maintain fenestration (with a $2.7-\mathrm{mm}$ punch) of the atrial septal defect patch in all patients. The opening will provide easy access to the left atrium for catheterization to assess hemodynamics and image and perform dilation on the Melody valve, as necessary. In addition, many of these children are known to have poor LV compliance because of underlying disease, and the fenestration will allow echocardiographic estimation of the transseptal gradient and, thus, the left atrial pressure.

An echocardiogram should be performed intraoperatively to assess the function of the prosthetic valve, rule out paravalvular leaks and LVOTO, and assess ventricular function, specifically, regional wall motion abnormalities in the circumflex territory.

\section{Postoperative Care}

The current practice has been to anticoagulate patients with heparin at a therapeutic dose (adjusting to an heparin level $>0.5 \mathrm{U} / \mathrm{mL}$ ) until aspirin therapy $(5-10 \mathrm{mg} / \mathrm{kg} / \mathrm{d})$ can be initiated. Aspirin responsiveness is tested using the Verify Now system (Accumetrics, Inc, San Diego, Calif) to ensure $<550$ aspirin reaction units. Nonresponders should be treated with clopidogrel. Antibiotic prophylaxis should be administered to all patients until the chest tubes have been removed. All patients should undergo echocardiographic evaluation before discharge. Cardiac catheterization will be scheduled for 3 to 6 months postoperatively or sooner, if the echocardiographic evaluation suggests an increasing transmitral gradient.

\section{RESULTS}

Eleven patients underwent Melody valve implantation (Table 1). The median age at implantation was 7 months (range, 2-28). Of the 11 patients, 8 were $<12$ months old. The median weight was $5.2 \mathrm{~kg}$ (range, 3.5-13.6). Of the 11 patients, 3 had an AVC defect, 1 had ischemic mitral regurgitation, and 7 had congenital mitral stenosis. All patients had undergone mitral or left atrioventricular valve repairs that had failed, and 1 patient had had bioprosthetic valve failure. The median number of previous surgical and/or catheter-based interventions was 3 (range, 3-6). The indication for MVR was severe mitral stenosis in 4 patients and severe mitral regurgitation in 7 .

The operative details are provided in Table 1. Melody valve modification included addition of a pericardial sewing cuff in 6 patients, removal of the proximal stent crowns in 5, removal of the distal stent crowns in 5, and aggressive resection of the LVOT-facing sinus in 1 patient. The native anterior leaflet with its subannular apparatus was preserved in 2 patients. The anterior leaflet was partially preserved in $5 \mathrm{pa}-$ tients. Fixation of the distal stent to the posterior left ventricle was performed in 7 patients. The maximum balloon size used for Melody valve expansion in the operating room was 9 to $16 \mathrm{~mm}$ (median, 14). The interatrial septum was reconstituted with patch material in 10 patients and fenestrated in 7 . The immediate postoperative transvalvular gradient ranged from 2 to $7 \mathrm{~mm} \mathrm{Hg}$ (median, 4), with mild or less mitral regurgitation in all patients. Two patients had mild LVOTO. Small paravalvular leaks were observed in 7 patients.

At a median follow-up of 3 months (range, 1-20), 1 patient had died. This patient had had heterotaxy, upstairs-downstairs ventricles, a double outlet right ventricle and an AVC defect, and ventricular dysfunction and had undergone biventricular repair. He had required extracorporeal membrane oxygenation for severe ventricular dysfunction. The patient subsequently underwent 

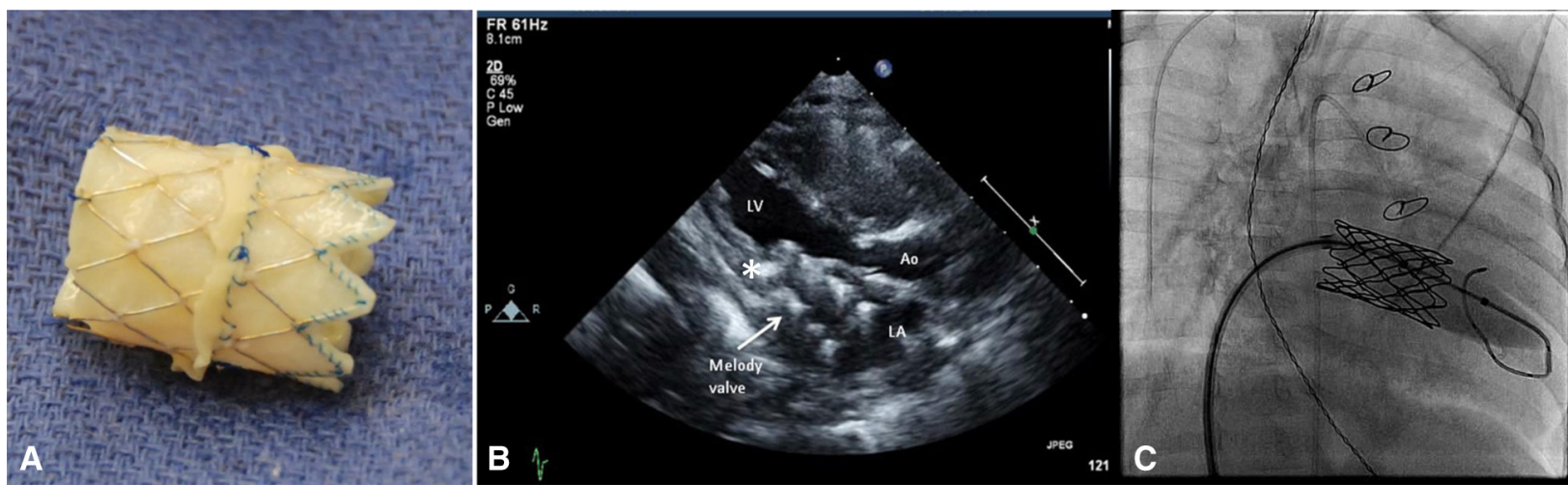

FIGURE 1. A, Melody valve modified by the addition of a sewing cuff and resection of stent crowns. B, Fixation $(*)$ of the distal stent to the inferior wall of the left ventricle prevents deviation of the distal stent into the left ventricular outflow tract. C, Catheter-based dilation of the valve 6 months after implantation. $A o$, Aorta; $C A$, left atrium; $L V$, left ventricle.

Melody valve implantation for a regurgitant left atrioventricular valve. However, he was unable to separate from extracorporeal membrane oxygenation. One patient underwent heart transplantation for ventricular dysfunction. One patient who had not undergone distal stent fixation underwent catheter-based reintervention for LVOTO. Significant paravalvular leaks developed in 2 patients; the leak was successfully treated by balloon expansion of the valve in 1 patient. Permanent pacemaker was implanted in 1 patient because of complete heart block. One patient has developed regurgitation due to leaflet perforation at early follow-up (2 months), presumably owing to an injury during pericardial cuff addition or endocarditis. Three patients have undergone successful catheter-based expansion of the Melody valve at a median interval of 6 months (range, 2-6), all with less than mild regurgitation and stenosis after valve expansion.

\section{DISCUSSION}

The present study reports our surgical experience and short-term follow-up data after MVR with the Melody valve. The acute hemodynamic performance of the valve was acceptable, with a low reoperation rate at short-term follow-up. The potential complications include LVOTO, paravalvular leaks, and conduction system injury. Melody valve expansion within 6 months after implantation was feasible, with maintenance of prosthetic function.

The Melody valve provides several advantages over other commercially available prostheses. The valve can be implanted into neonates or infants with annuli $<12 \mathrm{~mm}$. It is encased by a thin-walled conduit and stent, which provides a large effective orifice area and protects the leaflets from pannus ingrowth. The bovine jugular vein leaflet tissue is thin and pliable, which is suitable for the low cardiac output associated with infant circulation. If the valve can be percutaneously expanded as the child grows, it could delay the time to reoperation. Additional advances in transcatheter valve technology and valve-in-valve insertion techniques might allow for nonoperative replacement options.

One patient in the present series developed significant LVOTO owing to deviation of the distal aspect of the stent into the LVOT. Fixation of the distal portion of the stent to the posterior wall of the left ventricle will prevent migration toward the LVOT. Resection of the sinus of the valve facing the LVOT can prevent LVOTO but increases the risk of paravalvular leak. The patients who had undergone distal stent fixation without stent resection have not developed LVOTO. Stent resection to avoid LVOTO is not recommended for most patients but should be reserved for patients at the greatest risk of LVOTO-neonates with hypoplastic ventricles and pre-existing hypoplasia of the LVOT. Although stent resection did not impair early valve function in the present series, it could affect the long-term performance of the valve.

Most of the immediate small paravalvular leaks resolved within several months. Persistent, significant paravalvular leaks were observed in 2 patients. One patient underwent aggressive resection of the stent sinus, and both had undergone implantation without a pericardial sewing cuff. Apposition of the valve against the annulus by additional dilation might prevent leaks, just as might the use of the sewing cuff. In 1 patient, the paravalvular leak was managed by percutaneous dilation.

Our short-term follow-up data suggest that the Melody valve can be successfully dilated percutaneously after implantation. It is unclear whether this expandability will be possible beyond 6 months of age. The current version of the Melody valve can reach a maximum size of 22 $\mathrm{mm}$, which would be adequate into adolescence.

The Melody valve protrudes into the left atrium; however, pulmonary vein obstruction was not observed. Anchoring the valve to the LV posterior free wall resulted in anterior displacement of the proximal portion of the valve away from the pulmonary veins. However, the pulmonary 


\begin{tabular}{|c|c|c|c|c|c|c|c|}
\hline $\begin{array}{l}\text { Pt. } \\
\text { No. }\end{array}$ & $\begin{array}{r}\text { Age }(\mathbf{m o}) / \\
\text { weight }(\mathbf{k g})\end{array}$ & Diagnosis & Previous procedures & Operative details & $\begin{array}{c}\text { Postoperative } \\
\text { echocardiographic } \\
\text { findings } \\
\end{array}$ & $\begin{array}{l}\text { Last echocardiographic } \\
\text { and/or catheterization } \\
\text { findings }\end{array}$ & Follow-up data \\
\hline 1 & $3 / 4$ & $\begin{array}{l}\text { (S,D,S) Large malalignment } \\
\text { VSD, secundum ASD, mildly } \\
\text { hypoplastic MV and LV, } \\
\text { coarctation of aorta }\end{array}$ & $\begin{array}{l}\text { 1. Repair of coarctation, VSD, } \\
\text { and tricuspid valve } \\
\text { 2. Reimplantation of anterolateral } \\
\text { papillary muscle for rupture } \\
\text { (developed severe MR with } \\
\text { ruptured chords) }\end{array}$ & $\begin{array}{l}\text { MV leaflets and subvalvular } \\
\text { apparatus preserved } \\
\text { Stent shortened proximally and } \\
\quad \text { distally } \\
\text { No pericardial skirt } \\
\text { No LV tacking suture } \\
\text { Interrupted valve sutures } \\
\text { Valve dilated to } 12 \mathrm{~mm} \\
\text { Atrial septum closed with bovine } \\
\text { pericardium without } \\
\text { fenestration }\end{array}$ & $\begin{array}{l}\text { MS } 4 \text { mm Hg, no MR, } \\
\text { no paravalvular leak, } \\
\text { no LVOTO }\end{array}$ & $\begin{array}{l}\text { Echocardiogram: } \\
\text { MS } 4 \text { mm Hg, no MR, } \\
\text { no paravalvular leak, } \\
\text { no LVOTO }\end{array}$ & $\begin{array}{l}3 \mathrm{mo} \text {; heart } \\
\text { transplantation }\end{array}$ \\
\hline 2 & $9 / 5.3$ & $\begin{array}{l}\text { (S,D,S) Multiple VSDs, } \\
\text { parachute MV with } \\
\text { stenosis, aortic coarctation, } \\
\text { unicommissural aortic valve }\end{array}$ & $\begin{array}{l}\text { 1. Coarctation repair and PAB } \\
\text { 2. Repair of multiple VSDs, } \\
\text { pulmonary artery debanding, } \\
\text { MV repair } \\
\text { 3. MV balloon valvotomy } \\
\text { (developed severe MR and } \\
\text { moderate MS) }\end{array}$ & $\begin{array}{l}\text { MV leaflets and subvalvular } \\
\quad \text { apparatus excised } \\
\text { Stent not shortened } \\
\text { No pericardial skirt } \\
\text { No LV tacking suture } \\
\text { Continuous valve suture } \\
\text { Dilated to } 12 \mathrm{~mm} \\
\text { Atrial septum closed primarily } \\
\quad \text { without fenestration }\end{array}$ & $\begin{array}{l}\text { MS } 4 \mathrm{~mm} \mathrm{Hg} \text {, no MR, } \\
\text { small paravalvular } \\
\text { leak, LVOT } 13 \mathrm{~mm} \mathrm{Hg}\end{array}$ & $\begin{array}{l}\text { Catheterization: } \\
\text { MS } 5 \mathrm{~mm} \mathrm{Hg} \text {; no MR; } \\
\text { small paravalvular leak; } \\
\text { LVOTO } 50 \mathrm{~mm} \mathrm{Hg} \\
\text { (30 mm Hg Melody valve, } \\
20 \mathrm{~mm} \mathrm{Hg} \text { subaortic); } \\
\text { distal Melody side wall } \\
\text { dilated again for LVOT } \\
35 \mathrm{~mm} \mathrm{Hg} \mathrm{(15} \mathrm{mm} \mathrm{Hg} \\
\text { Melody, } 20 \mathrm{~mm} \mathrm{Hg} \\
\text { subaortic) }\end{array}$ & $20 \mathrm{mo}$ \\
\hline 3 & $15 / 8.5$ & $\begin{array}{l}\text { (S,D,S) MS, aortic stenosis, } \\
\text { small apex forming LV with } \\
\text { EFE and hypoplastic bicuspid } \\
\text { aortic valve }\end{array}$ & $\begin{array}{l}\text { 1) Ross procedure, LV EFE } \\
\text { resection, MV repair } \\
\text { 2) MV repeat repair } \\
\text { 3) MV replacement with 14-mm } \\
\text { porcine valve (developed } \\
\text { severe bioprosthetic stenosis) }\end{array}$ & $\begin{array}{l}\text { Bioprosthesis excised } \\
\text { Stent not shortened } \\
\text { No pericardial skirt } \\
\text { No LV tacking suture } \\
\text { Continuous valve suture } \\
\text { Valve dilated to } 16 \mathrm{~mm} \\
\text { Atrial septum closed with } \\
\text { CorMatrix* with fenestration }\end{array}$ & $\begin{array}{l}\text { MS } 6 \text { mm Hg; no MR; } \\
\text { no paravalvular leaks; } \\
\text { no LVOTO }\end{array}$ & $\begin{array}{l}\text { Catheterization: } \\
\text { MS } 4 \mathrm{~mm} \mathrm{Hg,} \mathrm{no} \mathrm{MR,} \\
\text { LVOT } 4 \mathrm{~mm} \mathrm{Hg} \\
\text { Echocardiogram: } \\
\text { no MS, no MR, no LVOTO }\end{array}$ & $12 \mathrm{mo}$ \\
\hline 4 & $4 / 4.4$ & $\begin{array}{l}(\mathrm{S}, \mathrm{D}, \mathrm{S}) \text { Unicommissural aortic } \\
\text { valve }\end{array}$ & $\begin{array}{l}\text { 1. Fetal aortic valve balloon } \\
\text { dilation } \times 2 \\
\text { 2. Postnatal aortic valve balloon } \\
\text { dilation } \times 3 \\
\text { 3. Ross procedure, } \mathrm{LV} \text { EFE } \\
\text { resection, mobilization of MV } \\
\text { papillary muscle (developed } \\
\text { rapidly progressing severe MS) }\end{array}$ & $\begin{array}{l}\text { MV leaflets and subvalvular } \\
\text { apparatus excised } \\
\text { Single stent tine cut to prevent } \\
\text { pulmonary vein stenosis } \\
\text { Pericardial skirt } \\
\text { LV tacking suture } \\
\text { Continuous valve suture } \\
\text { Valve dilated to } 14 \mathrm{~mm} \\
\text { Atrial septum closed with bovine } \\
\text { pericardium with fenestration }\end{array}$ & $\begin{array}{l}\text { MS } 4 \text { mm Hg; no MR; } \\
\text { single small } \\
\text { paravalvular leak; no } \\
\text { LVOTO }\end{array}$ & $\begin{array}{l}\text { Catheterization: } \\
\text { MS } 13 \mathrm{~mm} \mathrm{Hg} \text {, balloon } \\
\text { dilated to } 2 \mathrm{~mm} \mathrm{Hg} \text {; no } \\
\text { MR; no LVOTO } \\
\text { Echocardiogram: } \\
\text { MS } 6 \mathrm{~mm} \mathrm{Hg} \text {; no MR; no } \\
\text { paravalvular leak; no } \\
\text { LVOTO }\end{array}$ & $7 \mathrm{mo}$ \\
\hline
\end{tabular}


MV leaflets and subvalvular apparatus excised Stent shortened proximally Pericardial skirt

LV tacking suture Continuous valve suture

Valve dilated to $14 \mathrm{~mm}$

Atrial septum closed with bovine pericardium with fenestration

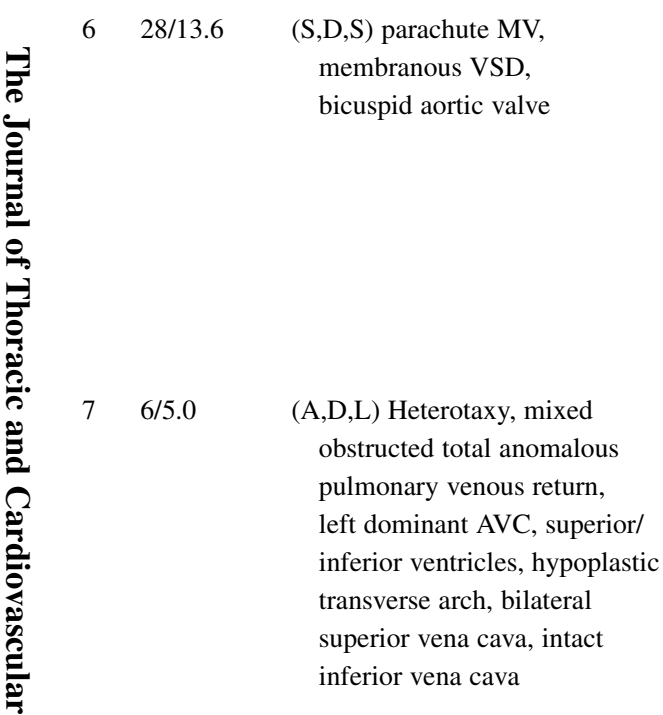

$8 \quad 2 / 3.5 \quad(\mathrm{~S}, \mathrm{D}, \mathrm{S})$ Balanced complete AVC defect

Continuous valve suture pulmonary venous return and Stent shortened distally, not

\begin{abstract}
1. MV balloon dilation
2. MV repair, VSD closure

MV leaflets and subvalvular

apparatus preserved

MV repeat repair (developed Stent not shortened

MS $2 \mathrm{~mm} \mathrm{Hg}$, no MR, 2 trivial paravalvular
\end{abstract}

acute severe MR from ruptured Pericardial skir

chords and moderate stenosis) No LV tacking suture

Valve dilated to $14 \mathrm{~mm}$

Atrial septum closed with

autologous pericardium

without fenestration

1. Aortic arch repair, repair of LAVV leaflets preserved left PAB proximally

2. Biventricular repair with AVC Pericardial skirt

repair, intra-atrial baffle of LV tacking suture

systemic veins to RAVV, Continuous valve suture

unroofing of pulmonary veins, Dilated to $14 \mathrm{~mm}$

arterial switch operation, baffle Baffle not fenestrated

of $\mathrm{LV}$ to neoaorta, $\mathrm{PAB}$

Unable to separate patient from

(residual moderate-severe MR) ECMO

1. Two patch repair of AVC

2. LAVV and RAVV repairs

(residual severe LAVV

regurgitation and moderate

stenosis)

valve, 2 smal

paravalvular leaks,

severe LV dysfunction

$4 \mathrm{~mm} \mathrm{Hg}$, no MR,

small paravalvular
Superior leaflet preserved, mural leaflet and associated

subvalvular apparatus excised

Stent crowns trimmed proximally

and distally

No pericardial skirt

Posterior LV fixation suture

Interrupted valve sutures

Dilated to $10 \mathrm{~mm}$

Atrial septum closed with bovine pericardium with fenestration
MS 4 mm Hg; no MR; Catheterization:

$6 \mathrm{mo}$

no paravalvular leak, MS $7 \mathrm{~mm} \mathrm{Hg}$, dilated to

no LVOTO

$4 \mathrm{~mm} \mathrm{Hg}$; no MR; no

LVOTO

Echocardiogram:

MS $8 \mathrm{~mm} \mathrm{Hg}$, no MR, no

paravalvular leak; trivial LVOTO

Catheterization:

MS $9 \mathrm{~mm} \mathrm{Hg}$; moderate

MR; no LVOTO

Echocardiogram:

Moderate MS $9 \mathrm{~mm} \mathrm{Hg}$;

moderate-severe MR;

possible vegetations on

valve leaflet and small

mass on LA side of stent

No flow across Melody None

Death

$6 \mathrm{mo}$; suspected

endocarditis;

Melody valve

replaced

Catheterization:

MS 6 mm Hg, no MR, no

2 mo; pacemaker

implanted

LVOT $5 \mathrm{~mm} \mathrm{Hg}$

Echocardiogram:

MS 5 mm Hg, no MR, no LVOTO 


\begin{tabular}{|c|c|c|c|c|c|c|c|}
\hline $\begin{array}{l}\text { Pt. } \\
\text { No. }\end{array}$ & $\begin{array}{c}\text { Age }(\mathbf{m o}) / \\
\text { weight }(\mathbf{k g})\end{array}$ & Diagnosis & Previous procedures & Operative details & $\begin{array}{c}\text { Postoperative } \\
\text { echocardiographic } \\
\text { findings }\end{array}$ & $\begin{array}{l}\text { Last echocardiographic } \\
\text { and/or catheterization } \\
\text { findings }\end{array}$ & Follow-up data \\
\hline 9 & $6 / 3.7$ & $\begin{array}{l}(\mathrm{S}, \mathrm{D}, \mathrm{S}) \text { Congenital mitral } \\
\text { stenosis and small LV }\end{array}$ & $\begin{array}{l}\text { 1. MV balloon dilation } \times 2 \\
\text { 2. MV repair (developed severe } \\
\text { MS and mild MR) }\end{array}$ & $\begin{array}{l}\text { MV leaflets and subannular } \\
\text { apparatus excised } \\
\text { Stent shortened and section } \\
\text { facing LVOT was cut out } \\
\text { No pericardial skirt } \\
\text { LV tacking suture } \\
\text { Continuous valve suture } \\
\text { Dilated to } 9 \mathrm{~mm} \text { in LV and } 12 \mathrm{~mm} \\
\text { in atrium creating a funnel or } \\
\text { tapered melody (owing to } \\
\text { concerns of small LV size) } \\
\text { Atrial septum closed with bovine } \\
\text { pericardium with fenestration }\end{array}$ & $\begin{array}{l}\text { MS } 7 \mathrm{~mm} \mathrm{Hg} \text {; no MR, } \\
\text { mild-moderate } \\
\text { paravalvular leak, no } \\
\text { LVOTO }\end{array}$ & None & $\begin{array}{l}1 \mathrm{mo} \text {; still in } \\
\text { hospital }\end{array}$ \\
\hline 10 & $7 / 5.9$ & $\begin{array}{l}\text { (S,D,S) Right-dominant } \\
\text { transitional AVC, parachute } \\
\text { LAVV with single papillary } \\
\text { muscle; hypoplasia of aortic } \\
\text { annulus, ascending aorta, } \\
\text { distal transverse arch, and } \\
\text { isthmus }\end{array}$ & $\begin{array}{l}\text { 1. Bilateral branch pulmonary } \\
\text { bands and ductal stent } \\
\text { 2. Biventricular repair with } \\
\text { LAVV and RAVV repairs, } \\
\text { takedown of PAB and ductal } \\
\text { stent, arch, and ascending aorta } \\
\text { reconstruction } \\
\text { 3. LAAV repair (developed } \\
\text { severe MS and moderate MR) }\end{array}$ & $\begin{array}{l}\text { Superior leaflet partially } \\
\text { preserved and mural leaflets } \\
\text { and associated subvalvular } \\
\text { apparatus excised } \\
\text { Stent shortened proximally } \\
\text { Pericardial skirt } \\
\text { LV tacking suture } \\
\text { Continuous valve suture } \\
\text { Dilated to } 14 \mathrm{~mm} \\
\text { Atrial septum closed with bovine } \\
\text { pericardium with fenestration }\end{array}$ & $\begin{array}{l}\text { MS } 5 \mathrm{~mm} \mathrm{Hg} \text {, no MR, } \\
\text { small paravalvular } \\
\text { leak, LVOT } 8 \mathrm{~mm} \mathrm{Hg}\end{array}$ & None & $\begin{array}{l}1 \text { mo; recently } \\
\text { discharged from } \\
\text { hospital }\end{array}$ \\
\hline 11 & $23 / 11.4$ & $\begin{array}{l}(\mathrm{S}, \mathrm{D}, \mathrm{S}) \text { Shone's complex with } \\
\text { parachute MV }\end{array}$ & $\begin{array}{l}\text { 1. Coarctation and VSD repair } \\
\text { 2. MV repair (developed severe } \\
\text { MR and mild MS; parents did } \\
\text { not want another attempt at } \\
\text { repair) }\end{array}$ & $\begin{array}{l}\text { Mitral leaflets and subvalvular } \\
\text { apparatus excised; part of } \\
\text { anterior leaflet preserved } \\
\text { Stent shortened distally, but not } \\
\text { proximally } \\
\text { Pericardial skirt } \\
\text { LV tacking suture } \\
\text { Continuous valve suture } \\
\text { Dilated to } 16 \mathrm{~mm} \\
\text { Atrial septum closed with bovine } \\
\text { pericardium with fenestration }\end{array}$ & $\begin{array}{l}\text { MS } 5 \mathrm{~mm} \mathrm{Hg} \text {, no MR, } \\
\text { no paravalvular leaks, } \\
\text { no LVOTO }\end{array}$ & $\begin{array}{l}\text { Catheterization: } \\
\text { MS } 2 \mathrm{~mm} \mathrm{Hg} \text {, no MR, no } \\
\text { paravalvular leaks, no } \\
\text { LVOTO }\end{array}$ & $\begin{array}{l}1 \text { mo; in hospital } \\
\text { for treatment of } \\
\text { pulmonary } \\
\text { hypertension } \\
\text { unrelated to } \\
\text { Melody valve }\end{array}$ \\
\hline
\end{tabular}

$P t$. No., Patient number; $(S, D, S)$, situs ambiguus, D-looped ventricles, L-transposed aorta; $V S D$, ventricular septal defect; $A S D$, atrial septal defect; $M V$, mitral valve; $P A B$, pulmonary artery banding; $L V$, left ventricle/ventricular; $M S$, mitral stenosis; $M R$, mitral regurgitation; $L V O T O$, left ventricular outflow tract obstruction; $L V O T$, left ventricular outflow tract; $E F E$, endocardial fibroelastosis; $L A$, left atrial; (A,D, $L$ ), situs ambiguus, D-looped ventricles, L-transposed aorta; $A V C$, atrioventricular canal defect; $R A V V$, right atrioventricular valve; $L A V V$, left atrioventricular valve; $E C M O$, extracorporeal membrane oxygenation. *CorMatrix ECM Technologies, Roswell, Ga. 
veins could be at risk in patients with small atria. Pacemaker insertion was necessary in 1 patient with an AVC defect. The atrioventricular node was likely injured by suture placement after complete resection of the anterior leaflet. Overexpansion of the valve could also contribute to injury of the conduction system.

Patient selection for the Melody valve has evolved since the first implantation. Neonates and infants are obvious candidates owing to the lack of suitable alternatives, although patients with valve annuli $>18 \mathrm{~mm}$ are unlikely to benefit from the current version of the Melody valve, because stented prosthetic options are available. One patient in our series required explantation because of development of leaflet perforation. Endocarditis or injury to the valve could not be excluded. Long-term follow-up is necessary to determine the durability of this valve before expanding its application to older children.

\section{CONCLUSIONS}

The Melody valve for MVR is an option for children with small annular diameters and has demonstrated the potential for percutaneous expansion in the short-term as the child grows. If long-term follow-up data suggest that the valve maintains competence with subsequent transcatheter expansions, it could reduce the need for reintervention until adolescence. Distal stent fixation, the addition of a pericardial cuff, and the avoidance of aggressive stent resection are recommended. Additional prospective evaluation of this device for MVR is warranted.

\section{References}

1. Adatia I, Moore PM, Jonas RA, Colan SD, Lock JE, Keane JF. Clinical course and hemodynamic observations after supraannular mitral valve replacement in infants and children. J Am Coll Cardiol. 1997;29:1089-94.

2. Selamet Tierney ES, Pigula FA, Berul CI, Lock JE, del Nido PJ, McElhinney DB. Mitral valve replacement in infants and children 5 years of age or younger: evolution in practice and outcome over three decades with a focus on supra-annular prosthesis implantation. J Thorac Cardiovasc Surg. 2008;136:954-61, 961.e1-3.

3. Alsoufi B, Manlhiot C, McCrindle BW, Al-Halees Z, Sallehuddin A, Al-Oufi S et al. Results after mitral valve replacement with mechanical prostheses in young children. J Thorac Cardiovasc Surg. 2010;139:1189-96, 1196.e1-2.

4. Raghuveer G, Caldarone CA, Hills CB, Atkins DL, Belmont JM, Moller JH. Predictors of prosthesis survival, growth, and functional status following mechanical mitral valve replacement in children aged $<5$ years, a multi-institutional study. Circulation. 2003;108(Suppl 1):II174-9.

5. McElhinney DB, Hellenbrand WE, Zahn EM, Jones TK, Cheatham JP, Lock JE et al. Short- and medium-term outcomes after transcatheter pulmonary valve placement in the expanded multicenter US melody valve trial. Circulation. 2010;122:507-16.

6. Hasan BS, McElhinney DB, Brown DW, Cheatham JP, Vincent JA Hellenbrand WE, et al. Short-term performance of the transcatheter Melody valve in high-pressure hemodynamic environments in the pulmonary and systemic circulations. Circ Cardiovasc Interv. 2011;4:615-20.

7. Abdullah I, Ramirez FB, McElhinney DB, Lock JE, del Nido PJ, Emani S. Modification of a stented bovine jugular vein conduit (Melody valve) for surgical mitral valve replacement. Ann Thorac Surg. 2012;94:e97-8. 